\title{
Effective treatment of late-onset noninfectious pulmonary complication with ruxolitinib in an 8-year-old boy
}

\begin{tabular}{|c|c|}
\hline $\begin{array}{l}\text { Copyright } \odot \text { The authors } 2021 \\
\text { This version is distributed under } \\
\text { the terms of the Creative } \\
\text { Commons Attribution Non- } \\
\text { Commercial Licence 4.0. For } \\
\text { commercial reproduction rights } \\
\text { and permissions contact } \\
\text { permissions@ersnet.org }\end{array}$ & itor: \\
\hline \multirow[t]{2}{*}{$\begin{array}{l}\text { Received: } 19 \text { June } 2021 \\
\text { Accepted: } 9 \text { July } 2021\end{array}$} & $\begin{array}{l}\text { exercise-induced dyspnoea, frequently appear } 8-12 \text { months after HSCT [6]. Lung biopsy is considered the } \\
\text { gold standard to establish a specific diagnosis; however, it is not always feasible in clinical practice, } \\
\text { especially in children. Therefore, the diagnosis of LONIPCs relies upon clinical manifestations, lung } \\
\text { imaging, spirometry, and the exclusion of infections [2]. First-line treatment is based on high-dose } \\
\text { corticosteroids, while second-line treatment includes immunosuppressive agents such as calcineurin } \\
\text { inhibitors [2]. Inhaled corticosteroids and short/long-acting bronchodilators may be slightly effective [7]. } \\
\text { Ruxolitinib is a selective inhibitor of JAK1/2 approved for acute GVHD (in patients >12 years of age) [8], } \\
\text { which has recently been proposed for chronic GVHD and LONIPCs [9]. }\end{array}$ \\
\hline & 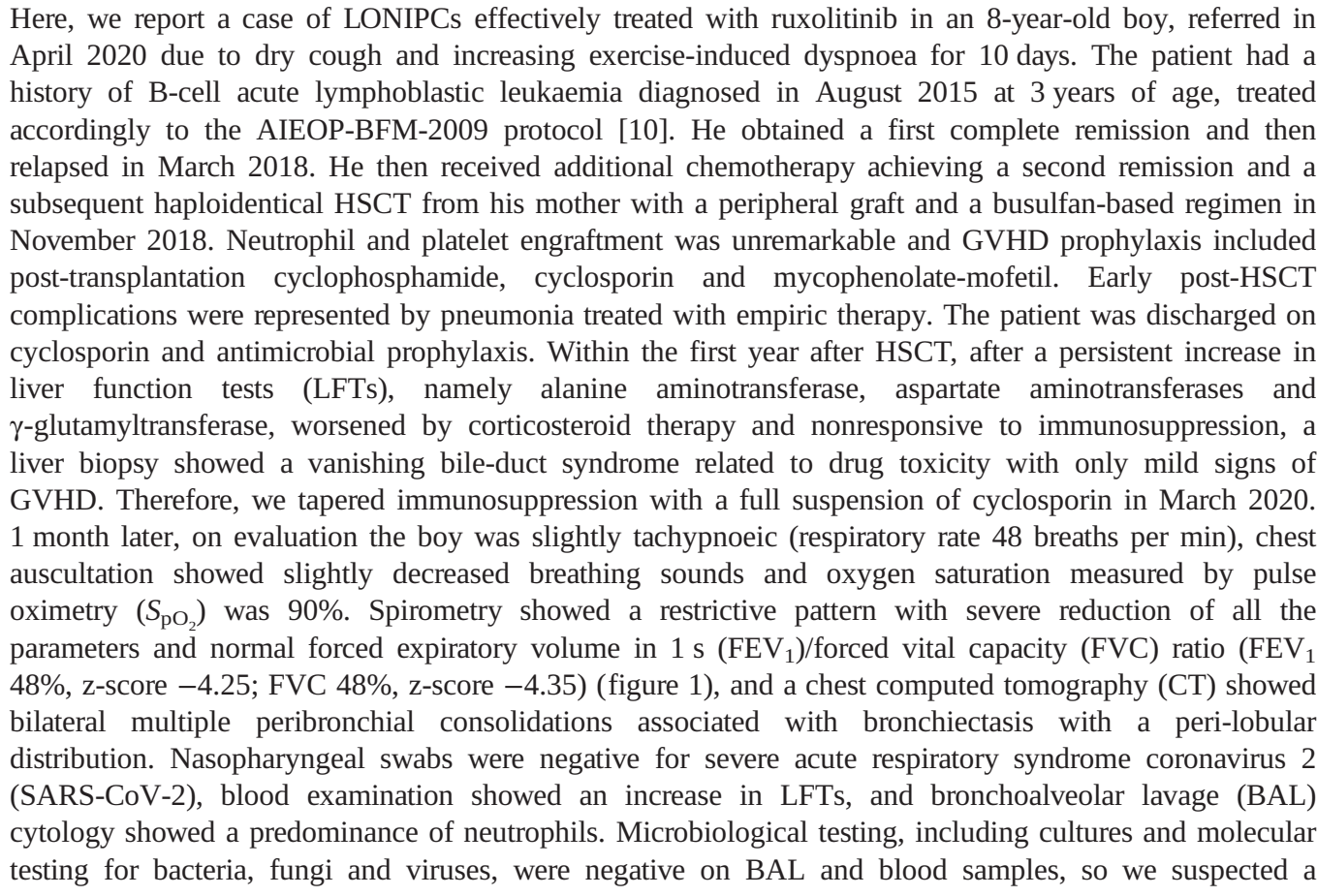 \\
\hline \multirow[t]{2}{*}{$\begin{array}{l}\text { Check for } \\
\text { updates }\end{array}$} & $\begin{array}{l}\text { Shareable abstract (@ERSpublications) } \\
\text { Ruxolitinib could be considered as an option in the treatment of LONIPCs in children when other } \\
\text { treatments are ineffective. Spirometry is a valuable tool for both diagnosis and follow-up of } \\
\text { LONIPCs in children. https://bit.ly/3BmOYfb }\end{array}$ \\
\hline & $\begin{array}{l}\text { Cite this article as: Di Cicco M, Del Tufo E, Parolo E, et al. Effective treatment of late-onset } \\
\text { noninfectious pulmonary complication with ruxolitinib in an 8-year-old boy. ERJ Open Res 2021; } 7 \text { : } \\
00407-2021 \text { [DOI: } 10.1183 / 23120541.00407-2021] \text {. }\end{array}$ \\
\hline
\end{tabular}




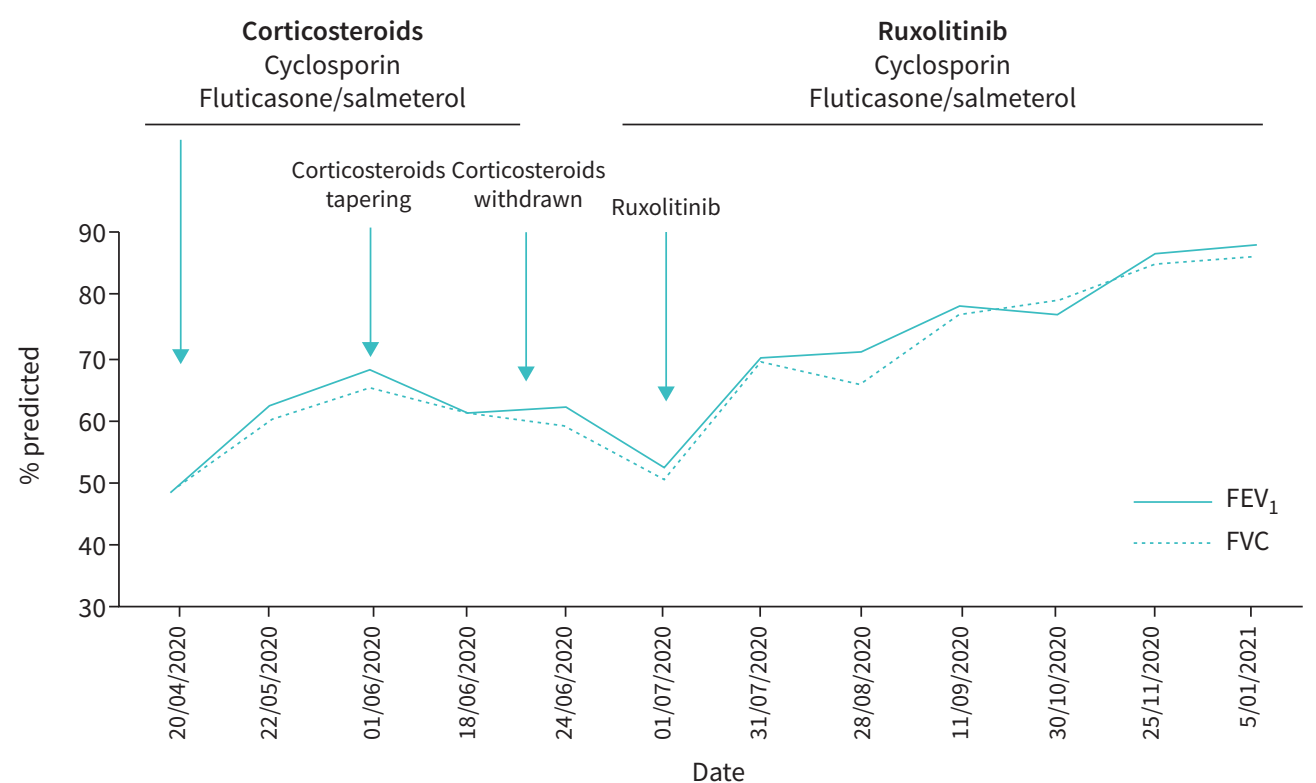

FIGURE 1 Lung function testing trend by means of forced expiratory volume in $1 \mathrm{~s}\left(\mathrm{FEV}_{1}\right)$ and forced vital capacity (FVC) values.

LONIPC. The patient required low-flow oxygen, while cyclosporin, high-dose prednisone and inhaled salmeterol/fluticasone were initiated, with a gradual improvement of both symptoms and spirometry (FEV 1 62\%, z-score -3.12, FVC 60\%, z-score -3.32). 1 month later, chest CT showed a reduction of the parenchymal consolidations, but fibrotic bands were observed in the same areas and were associated with traction bronchiectasis, suggesting a fibrotic evolution. On tapering the steroids, the patient worsened again both clinically (dyspnoea on exertion, $S_{\mathrm{pO}_{2}}$ 94\%) and at spirometry ( $\mathrm{FEV}_{1}$ 52\%, z-score -3.95). Prednisone was increased again, but it had to be stopped due to a further increase in LFTs. Then, ruxolitinib was introduced (10 mg per day), with subsequent gradual improvement. Remarkably, 7 months later both LFTs and spirometry were normal $\left(\mathrm{FEV}_{1} 88 \%\right.$, z-score -1.05; FVC 86\%, z-score -1.18) (figure 1). To further characterise the pulmonary damage and in the attempt to avoid additional radiation exposure, lung magnetic resonance imaging (MRI) was performed in February 2021, revealing a reduction of the parenchymal bands and striae. T2-weighted sequences were consistent with chronic inflammatory involvement and initial fibrosis.

To our knowledge, this is the first reported effective treatment of LONIPCs with ruxolitinib in a child younger than 12 years with complete normalisation of lung function testing. LONIPCs is a generic definition including different subtypes of inflammatory lung involvement, potentially leading to aberrant tissue repair [11]. Among them, interstitial disease, bronchiolitis obliterans syndrome (BOS), and cryptogenic organising pneumonia (COP), are the most common [12]. According to the American Thoracic Society/European Respiratory Society guidelines [13], in LONIPCs the flow-volume curve may show an obstructive pattern (BOS), a restrictive pattern (interstitial disease), or even a mixed pattern [4]. CT may show geographic hypoattenuation and air trapping with a subpleural predominance in BOS, airspace consolidation along the bronchovascular bundle or in the subpleural area in COP, or ground-glass areas with reticulation and crazy paving pattern with predominantly peribronchovascular traction bronchiectasis in interstitial disease [14]. In our case, respiratory signs and symptoms appeared more than 1 year after transplantation, when cyclosporin was discontinued, and without any relationship with hepatic toxicity, suggesting the presence of an underlying alloreactive status that was exacerbated by the removal of immunosuppression. Moreover, lung infections were excluded, a restrictive pattern was identified on spirometry, and interstitial damage together with bronchiectasis was shown at CT, while MRI confirmed the presence of chronic inflammatory damage with fibrosis. In the absence of a diriment histological finding, while neither the BOS nor COP criteria were met, interstitial lung disease was a reasonable diagnosis.

Ruxolitinib can control alloreactivity through: 1) suppression of pro-inflammatory cytokines, 2) increase in regulatory T-cells, and 3) decrease in memory T-cells [15]. However, its safety and efficacy in children is 
still uncertain. Data on the effects of ruxolitinib on lung function in LONIPCs are lacking and only one study included five children with BOS showing that steroids were reduced in four patients, a full suspension was achieved in three patients and a $24 \%$ increase in $\mathrm{FEV}_{1}$ was observed [16]. Our patient responded to high-dose steroids, but the treatment was discontinued due to hepatic toxicity; since cyclosporin was not sufficient to control lung involvement, ruxolitinib was a valuable and effective option, providing a clinical response and a definite improvement of lung function. We also observed an improvement of lung involvement at the MRI. Our case shows that spirometry is a valuable tool for both diagnosis and follow-up of LONIPCs in children since lung auscultation may be unremarkable. Our case report suggests that ruxolitinib should be considered as an effective option in the treatment of LONIPCs in children when other treatments are not effective nor feasible. However, more studies are needed to further investigate its efficacy and long-term safety in this age group.

\section{Maria Di Cicco $\oplus^{1}$, Ester Del Tufo ${ }^{1}$, Eva Parolo ${ }^{1}$, Mariacristina Menconi ${ }^{2}$, Sayla Bernasconi ${ }^{2}$, Chiara Romei ${ }^{3}$, Alessandro Di Gangi $\oplus^{1}$, Beatrice Masini ${ }^{1}$, Diego Peroni ${ }^{1}$ and Gabriella Casazza ${ }^{2}$}

${ }^{1}$ Dept of Clinical and Experimental Medicine, Section of Pediatrics, University of Pisa, Pisa, Italy. ${ }^{2}$ Pediatric Onco-haematology Unit, Pisa University Hospital, Pisa, Italy. ${ }^{3}$ Dept of Diagnostic Imaging, 2nd Radiology Unit, Pisa University Hospital, Pisa, Italy.

\section{Corresponding author: Maria Di Cicco (maria.dicicco@unipi.it)}

Provenance: Submitted article, peer reviewed.

Authors contributions: M. Di Cicco, E. Del Tufo, E. Parolo and M. Menconi conceptualised and designed the study, drafted the initial manuscript, contributed to data collection, and reviewed and critically revised the final manuscript. A. Di Gangi, B. Masini and C. Romei contributed to data collection and to the review of the literature, and actively participated in manuscript drafting. S. Bernasconi, G. Casazza and D. Peroni actively participated in manuscript drafting, and reviewed and critically revised the final manuscript. All authors approved the final manuscript as submitted and agree to be accountable for all aspects of the work.

Ethics statement: Written informed consent was obtained from the patient's parents for publication of this case report and any accompanying images.

Conflict of interest: The authors have no conflicts of interest relevant to this article to disclose.

References

1 Patriarca F, Skert C, Sperotto A, et al. Incidence, outcome, and risk factors of late-onset noninfectious pulmonary complications after unrelated donor stem cell transplantation. Bone Marrow Transplant 2004; 33: 751-758.

2 Carreras E, Cooke KR. Noninfectious pulmonary complications. In: Carreras E, Dufour C, Mohty M, et al., eds. The EBMT Handbook: Hematopoietic Stem Cell Transplantation and Cellular Therapies. 7th Edn. Cham, Springer, 2019; pp. 393-407.

3 Palmas A, Tefferi A, Myers JL, et al. Late-onset noninfectious pulmonary complications after allogeneic bone marrow transplantation. Br J Haematol 1998; 100: 680-687.

4 Hildebrandt GC, Fazekas T, Lawitschka A, et al. Diagnosis and treatment of pulmonary chronic GVHD: report from the consensus conference on clinical practice in chronic GVHD. Bone Marrow Transplant 2011; 46: 1283-1295.

5 Bergeron A, Chevret S, Peffault de Latour R, et al. Noninfectious lung complications after allogeneic haematopoietic stem cell transplantation. Eur Respir J 2018; 51: 1702617.

6 Trisolini R, Bandini G, Stanzani M, et al. Morphologic changes leading to bronchiolitis obliterans in a patient with delayed non-infectious lung disease after allogeneic bone marrow transplantation. Bone Marrow Transplant 2001; 28: 1167-1170.

7 De Soyza A, Fisher AJ, Small T, et al. Inhaled corticosteroids and the treatment of lymphocytic bronchiolitis following lung transplantation. Am J Respir Crit Care Med 2001; 164: 1209-1212.

8 Przepiorka D, Luo L, Subramaniam S, et al. FDA approval summary: ruxolitinib for treatment of steroid-refractory acute graft-versus-host disease. Oncologist 2020; 25: e328-e334.

9 Streiler C, Shaikh F, Davis C, et al. Ruxolitinib is an effective steroid sparing agent in bronchiolitis obliterans due to chronic graft-versus-host-disease. Bone Marrow Transplant 2020; 55: 1194-1196. 
10 clinicaltrials.gov. International Collaborative Treatment Protocol For Children And Adolescents With Acute Lymphoblastic Leukemia (Phase III). ClinicalTrials.gov Identifier: NCT01117441. https://clinicaltrials.gov/ct2/ show/study/NCT01117441 Date last accessed: 6 July 2021.

11 Barker AF, Bergeron A, Rom WN, et al. Obliterative bronchiolitis. N Engl J Med 2014; 370: 1820-1828.

12 Nishio N, Yagasaki $\mathrm{H}$, Takahashi $\mathrm{Y}$, et al. Late-onset non-infectious pulmonary complications following allogeneic hematopoietic stem cell transplantation in children. Bone Marrow Transplant 2009; 44: 303-308.

13 Pellegrino R, Viegi G, Brusasco V, et al. Interpretative strategies for lung function tests. Eur Respir J 2005; 26: 948-968.

14 Merlini L, Borzani IMO, Anooshiravani M, et al. Correlation of lung abnormalities on high-resolution CT with clinical graft-versus-host disease after allogeneic versus autologous bone marrow transplantation in children. Pediatr Radiol 2008; 38: 1201-1209.

15 Spoerl S, Mathew NR, Bscheider M, et al. Activity of therapeutic JAK $1 / 2$ blockade in graft-versus-host disease. Blood 2014; 123: 3832-3842.

16 Schoettler M, Duncan C, Lehmann L, et al. Ruxolitinib is an effective steroid sparing agent in children with steroid refractory/dependent bronchiolitis obliterans syndrome after allogenic hematopoietic cell transplantation. Bone Marrow Transplant 2019; 54: 1158-1160. 